\title{
The Cross-Sectional Study of Quality of Life of Caregivers of Mentally Retarded Children in S District of Chongqing China
}

\author{
Wenxia Li1,2,3*, Lijun Wang1,2,3*, Qian Peng ${ }^{1,2,3 *}$, Xue Du',2,3* Jun Ma1,2,3\# \\ ${ }^{1}$ School of Public Health and Management, Chongqing Medical University, Chongqing, China \\ ${ }^{2}$ Research Center for Medicine and Social Development, Chongqing Medical University, Chongqing, China \\ ${ }^{3}$ Collaborative Innovation Center of Social Risks Governance in Health, Chongqing Medical University, Chongqing, China \\ Email: *fairlily1117@163.com
}

How to cite this paper: Li, W.X., Wang, L.J., Peng, Q., Du, X. and Ma, J. (2020) The Cross-Sectional Study of Quality of Life of Caregivers of Mentally Retarded Children in S District of Chongqing China. Open Access Library Journal, 7: e6986.

https://doi.org/10.4236/oalib.1106986

Received: November 12, 2020

Accepted: December 15, 2020

Published: December 18, 2020

Copyright $\odot 2020$ by author(s) and Open Access Library Inc.

This work is licensed under the Creative Commons Attribution International License (CC BY 4.0).

http://creativecommons.org/licenses/by/4.0/

\begin{abstract}
Introduction: Caregivers are crucial providers of lifelong care for mentally retarded children due to their specific disability, and their rehabilitation training and living standards are closely related to caregivers' quality of life. Therefore, this study selected S District of Chongqing to conduct a cross-sectional study on the quality of life of caregivers of mentally retarded children. Methodology: The study was conducted at three specialized rehabilitation centers in Chongqing, China, using Basic Information Questionnaire and Generic Quality of Life Inventory-74 for caregivers of mentally retarded children, and the study sample included 112 caregivers of mentally retarded children and 104 normal children's caregivers. Results: The caregivers of mentally retarded children have higher scores than those of normal children. There are significant differences among them in the quality of life and in material condition caused by family annual income, in material condition caused by home address, in social function caused by father's occupation, and in material condition and in psychological function caused by father's education level. Conclusion: The caregivers of mentally retarded children have lower quality of life than those of normal children. Some demographic variables like the annual family income, home address, father's occupation and father's education level have effects on caregivers' quality of life.
\end{abstract}

\section{Subject Areas}

Cognitive Disorders, Psychology, Public Health

\footnotetext{
${ }^{\bar{x}}$ These authors contributed equally to this work.

\#Corresponding author.
} 


\section{Keywords}

Mentally Retarded, Children, Caregivers, Quality of Life, China

\section{Introduction}

"The disabled are a specially difficult group that requires extra care and special attention" [1]. The World Health Organization reported that over one billion people live with any type of a disability, which corresponds to approximately $15 \%$ of the world's population [2], and the number of disabled people in China ranks the highest in the world [3]. Disabled children are the most vulnerable ones among the disabled. Moreover, a wide concern should pay to mentally retarded children for their large number and unique obstacle characteristics. According to the 2nd National Disability Sample Survey of the China Disabled Person's Federation, there are more than 5 million disabled children [4], which is increasing by about 200,000 per year [5], and over 1.75 million mentally retarded children, which is the largest proportion among the disabled. In terms of disability characteristics, mentally retarded children cannot meet normal living needs in important life skills like speech, cognition and behavior due to significant mental function impairments, so they have to rely on their families for a long time or even for life in their daily life, social adaption, survival and development, etc. $83.2 \%$ of the parents perceived high levels of family burden [6] Therefore, a larger population of parents bears the monumental responsibility of rehabilitation, life care, survival and development of mentally retarded children.

As the most important support of mentally retarded children, the economic, spiritual and quality of life of caregivers are closely related to the rehabilitation and living standards of mentally retarded children [7]. Hence, improving the quality of life of caregivers of mentally retarded children is the core of promoting the survival and development of mentally retarded children, which is the part most that needs social support. In addition, the Chinese government has increased its concern and support for disabled groups in recent years, and has proposed slogans such as "focus on special groups", "completely build a well-off society in 2020, every disabled people included" [8]. Then, it is especially important to improve the quality of life of caregivers of mentally retarded children in this social context, which not only conduces to ensure the rehabilitation and living standards of mentally retarded children and thus promotes the survival and development of them, but also is an important indicator to measure the effectiveness of support policies and measures for rehabilitation, medical care and education of mentally retarded children [9].

Therefore, we selected the S District of Chongqing, China as the survey site to study the quality of life of mentally retarded children's caregivers and its influencing factors. This study explores the dilemmas and expectations from the perspective of caregivers to reflect and improve the quality of life of mentally re- 
tarded children and their parents. Furthermore, it can provide reference for further improving the relevant policies and service systems for mentally retarded children and other disabled children, so as to promote the survival and development of mentally retarded children and their caregivers, which is of great practical significance for improving the rehabilitation of mentally retarded children and promoting social harmony and stability.

\section{Methods}

\subsection{Research Ethics}

This research strictly abides by research ethics. Above all, we strictly follow the principle of voluntary participation based on being fully informed. Secondly, we fully respect their personality rights in the course of conducting the investigation, being practical and realistic and strictly following the principle of no harm and no deception. Additionally, we fully respect their privacy rights and strictly follow the principle of anonymity and confidentiality for all survey data. The study was approved by the Ethics Committee of Chongqing Medical University (Appendix).

\subsection{Research Design}

The mentally retarded children are managed by districts in Chongqing. The $S$ district, located in central downtown of Chongqing, has vast resources in medical, rehabilitation, education and others, so it has advantages in the rehabilitation training of mentally retarded children. Therefore, we take the $S$ district of Chongqing as an example to study the quality of life of caregivers of mentally retarded children. The respondents are caregivers of mentally retarded children in the S district of Chongqing.

We selected three qualified and well-regulated rehabilitation centers for mentally retarded children in the $S$ district of Chongqing due to the respondents' particularity, sensitivity, and resistance to the investigation. We selected the respondents from three rehabilitation centers by random sampling. All survey scales are filled out based on voluntary principle. We surveyed 152 respondents and collected 112 valid questionnaires from April 2018 to June 2018. The response rate of questionnaire was $73.68 \%$. In addition, we also surveyed the quality of life of 104 normal children's caregivers in the nearby primary schools as a control.

\subsection{Investigative Tools}

\subsubsection{Basic Information Questionnaire}

The Basic Information Questionnaire consists of the basic information of caregivers, of children and of family. The basic information of caregivers includes family role, age and home address; the basic information of child includes child's gender, age, single-child or not, the degree of intellectual disability, etc. The basic family information includes parents' marital status, parents' occupation, 
parents' education level, family's annual income, and annual rehabilitation expenses, etc.

\subsubsection{Generic Quality of Life Inventory-74 (GQOLI-74)}

The Generic Quality of Life Inventory-74 (GQOLI-74) presents four-dimension structure, namely physical function, mental function, social function, and material life states, including 20 factors and 74 items. The statistic analysis indexes include score of each factor, score of each dimension and total score. The higher scores are, the better their quality of life is. Each dimension, even each factor of the scale includes an evaluation of objective state (objective indicators) and subjective satisfaction (subjective indicators). GQOLI-74 is not only a viable measurement of the quality of life of the general population in one community, but also a comprehensive assessment questionnaire for the quality of life of specific populations (such as chronic patients, the elderly, parents of disabled children, etc.) [10] [11] [12]. The scale shows good reliability, validity and sensitivity after statistical testing (Chronbach $\alpha=0.7963$ ).

\subsection{Statistical Analysis}

The database was built by Excel 2007 software, and the data surveyed were statistically analyzed using SPSS 23.0 software. The normality test and homogeneity of variance test were conducted in the scores of the quality of life and of each dimension of case group and control group. It was found that all of them presented normal distribution and homoscedasticity. Therefore, we adopted t-test of binary variable data, one-way ANOVA of multi-classification variable data, and Pearson's correlation analysis, etc. Level of the test is $0.05(\alpha=0.05)$.

\section{Results}

\subsection{Basic Information}

The size of the research is 216 caregivers, including 112 caregivers of mentally retarded children (case group) and 104 caregivers of normal children (control group). The basic information of the sample is shown in Table 1, including caregiver's information (family role, age), children's information (gender, age, degree of intellectual disability), parents' information (occupation, education level, marital status) and family condition (number of children, home address, family's annual income and annual rehabilitation costs).

\subsection{The Characteristics of Respondents' Quality of Life}

Through statistical analysis of the scores of respondents in GQOLI-74, it shows that the total score of their quality of life is $55.11 \pm 10.97$. The highest value is the physical function (57.51), and the lowest one is the material life condition (51.65) among the four dimensions. More details are shown in Table 2.

Through statistical analysis of the frequency of the score of their quality of life, it is observed that the score of their quality of life is large-span, that about $70 \%$ 
Table 1. Basic information of the sample.

\begin{tabular}{|c|c|c|c|c|c|}
\hline Basic information & $\begin{array}{c}\text { Number of } \\
\text { case group } \\
(\mathrm{P} \%)\end{array}$ & $\begin{array}{l}\text { Number of } \\
\text { control group } \\
(\mathrm{P} \%)\end{array}$ & Basic information & $\begin{array}{c}\text { Number of } \\
\text { case group } \\
(\mathrm{P} \%)\end{array}$ & $\begin{array}{c}\text { Number of } \\
\text { control group } \\
(\mathrm{P} \%)\end{array}$ \\
\hline Family role & & & Father's occupation & & \\
\hline Father & $18(16.1)$ & $20(19.2)$ & Self-employed or freelancer & $17(15.2)$ & $14(13.5)$ \\
\hline Mother & $74(66.1)$ & $80(77.0)$ & $\begin{array}{c}\text { Worker in enterprise and } \\
\text { public institution }\end{array}$ & $75(67.0)$ & $84(80.8)$ \\
\hline Grandparents & $11(9.8)$ & $4(3.8)$ & Farmer & $9(8.0)$ & $1(0.9)$ \\
\hline Others & $9(8.0)$ & $0(0.0)$ & Unemployed & $11(9.8)$ & $5(4.8)$ \\
\hline Age $(x)$ & & & Mother's occupation & & \\
\hline$x \leq 30$ & $31(27.6)$ & $5(4.8)$ & Self-employed or freelancer & $13(11.6)$ & $17(16.3)$ \\
\hline $30<x \leq 40$ & $50(44.6)$ & $75(72.1)$ & $\begin{array}{l}\text { Worker in enterprise and } \\
\text { public institution }\end{array}$ & $42(37.5)$ & $66(63.5)$ \\
\hline $40<x \leq 50$ & $17(15.2)$ & $18(17.3)$ & Farmer & $11(9.8)$ & $2(1.9)$ \\
\hline $50<x \leq 60$ & $7(6.3)$ & $3(2.9)$ & Unemployed & $46(41.1)$ & $19(18.3)$ \\
\hline$x>60$ & $7(6.3)$ & $3(2.9)$ & Father's education level & & \\
\hline Gender of children & & & Master or above & $6(5.4)$ & $8(7.7)$ \\
\hline Male & $84(75.0)$ & $51(49.0)$ & Undergraduate & $48(42.8)$ & $44(42.3)$ \\
\hline Female & $28(25.0)$ & $53(51.0)$ & High school & $24(21.4)$ & $32(32.7)$ \\
\hline Age of children(y) & & & Middle school & $27(24.1)$ & $18(17.3)$ \\
\hline$y \leq 3$ & $32(28.6)$ & $8(7.7)$ & Elementary or below & $7(6.3)$ & $0(0.0)$ \\
\hline $3<y \leq 6$ & $39(34.8)$ & $37(35.6)$ & Mother's education level & & \\
\hline $6<y \leq 9$ & $24(21.4)$ & $11(10.6)$ & Master or above & $2(1.8)$ & $6(5.8)$ \\
\hline $9<\mathrm{y} \leq 12$ & $9(8.1)$ & $48(46.1)$ & Undergraduate & $54(48.2)$ & $51(49.0)$ \\
\hline $12<y \leq 15$ & $5(4.4)$ & $0(0.0)$ & High school & $18(16.1)$ & $32(30.8)$ \\
\hline $15<y \leq 18$ & $3(2.7)$ & $0(0.0)$ & Middle school & $30(26.8)$ & $13(12.5)$ \\
\hline Age of children (y) & & & Elementary or below & $8(7.1)$ & $2(1.9)$ \\
\hline$y \leq 3$ & $32(28.6)$ & $8(7.7)$ & Mother's education level & & \\
\hline $3<y \leq 6$ & $39(34.8)$ & $37(35.6)$ & Master or above & $2(1.8)$ & $6(5.8)$ \\
\hline $6<y \leq 9$ & $24(21.4)$ & $11(10.6)$ & Undergraduate & $54(48.2)$ & $51(49.0)$ \\
\hline $9<y \leq 12$ & $9(8.1)$ & $48(46.1)$ & High school & $18(16.1)$ & $32(30.8)$ \\
\hline $12<y \leq 15$ & $5(4.4)$ & $0(0.0)$ & Middle school & $30(26.8)$ & $13(12.5)$ \\
\hline $15<y \leq 18$ & $3(2.7)$ & $0(0.0)$ & Elementary or below & $8(7.1)$ & $2(1.9)$ \\
\hline
\end{tabular}




\section{Continued}

\begin{tabular}{|c|c|c|c|c|c|}
\hline Number of children & & & Family's annual income (z) & & \\
\hline 1 & $68(60.7)$ & $60(57.7)$ & $\mathrm{z} \leq 30,000$ & $33(29.4)$ & $9(8.7)$ \\
\hline 2 & $39(34.8)$ & $43(41.4)$ & $30,000<\mathrm{z} \leq 80,000$ & $49(43.8)$ & $42(40.4)$ \\
\hline 3 & $5(4.5)$ & $1(0.9)$ & $80,000<\mathrm{z} \leq 300,000$ & $27(24.1)$ & $39(37.5)$ \\
\hline Home address & & & $300,000<\mathrm{z} \leq 1,000,000$ & $3(2.7)$ & $11(10.5)$ \\
\hline Downtown & $59(52.7)$ & $38(36.5)$ & $z>1,000,000$ & $0(0.0)$ & $3(2.9)$ \\
\hline Township & $20(17.8)$ & $43(41.3)$ & Annual rehabilitation costs (s) & & \\
\hline Countryside & $33(29.5)$ & $23(22.2)$ & $\mathrm{s} \leq 10,000$ & $14(12.5)$ & $* * *$ \\
\hline Degree of intellectual disability & & & $10,000<s \leq 30,000$ & $27(24.1)$ & $* * *$ \\
\hline Mild & $27(24.1)$ & $* * *$ & $30,000<\mathrm{s} \leq 50,000$ & $29(25.9)$ & $* * *$ \\
\hline Moderate & $42(37.5)$ & $* * *$ & $50,000<s \leq 70,000$ & $17(15.2)$ & $* * *$ \\
\hline Severe & $32(28.6)$ & $* * *$ & $70,000<s \leq 100,000$ & $12(10.7)$ & $* * *$ \\
\hline Unknown & $11(9.8)$ & $* * *$ & $s \geq 100,000$ & $13(11.6)$ & $* * *$ \\
\hline \multicolumn{6}{|l|}{ The marital status of parents } \\
\hline Single & $3(2.7)$ & $0(0.0)$ & & & \\
\hline Married & $90(80.3)$ & $92(88.5)$ & & & \\
\hline Separated & $3(2.7)$ & $2(1.9)$ & & & \\
\hline Divorced & $5(4.5)$ & $6(5.8)$ & & & \\
\hline Remarried & $11(9.8)$ & $3(2.9)$ & & & \\
\hline Widowed & $0(0.0)$ & $1(0.9)$ & & & \\
\hline
\end{tabular}

${ }^{* * *}$ : no relevant data.

Table 2. The overall situation of the quality of life of and its dimensions of respondents.

\begin{tabular}{cccccc}
\hline & Total & $\begin{array}{c}\text { Material } \\
\text { condition }\end{array}$ & $\begin{array}{c}\text { Physical } \\
\text { function }\end{array}$ & $\begin{array}{c}\text { Psychological } \\
\text { function }\end{array}$ & $\begin{array}{c}\text { Social } \\
\text { function }\end{array}$ \\
\hline Mean & 55.11 & 51.65 & 57.51 & 54.47 & 56.81 \\
SD & 10.97 & 14.45 & 13.30 & 14.42 & 11.08 \\
Max & 92.42 & 83.98 & 97.50 & 97.92 & 95.00 \\
Min & 28.37 & 15.31 & 21.25 & 17.92 & 18.75 \\
\hline
\end{tabular}

of them range from 45 to 65 , indicating that their quality of life is in a general condition and most of them are at a medium or low level. More details are shown in Figure 1.

The results of the t-test between case group and control group in scores of the quality of life are shown in Table 3. The differences in quality of life between case group and control group are statistically significant. 


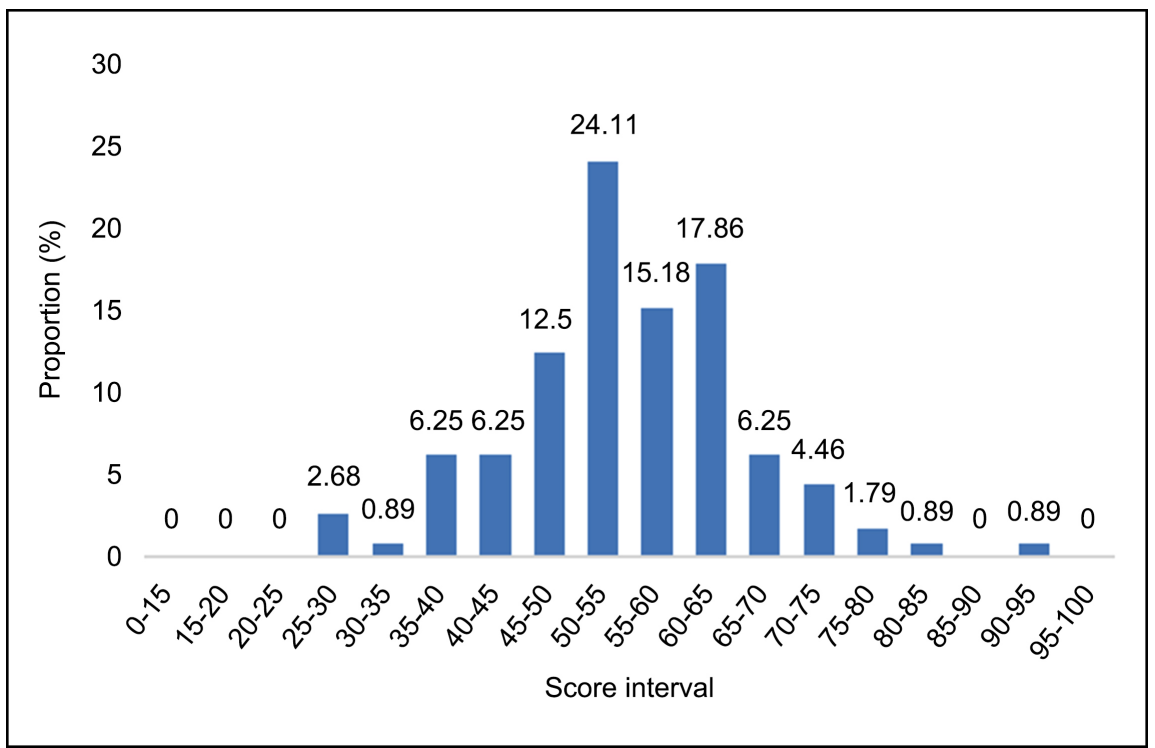

Figure 1. Frequency graph of sores of life quality. Note: The score interval does not include the small value, for example, the 0 to 15 range $(\mathrm{X})$ refers to $0<\mathrm{X} \leq 15$.

Table 3. Difference test of the quality of life of case group and of control group $(\bar{X} \pm s)$.

\begin{tabular}{ccccc}
\hline & Case group & Control group & $\mathrm{t}$ & $\mathrm{p}$ \\
\hline Total & $55.11 \pm 10.97$ & $72.00 \pm 11.15$ & -11.218 & $0.000^{* *}$ \\
Material condition & $51.65 \pm 14.45$ & $72.26 \pm 13.23$ & -10.907 & $0.000^{* *}$ \\
Physical function & $57.51 \pm 13.30$ & $74.33 \pm 11.58$ & -9.874 & $0.000^{* *}$ \\
Psychological function & $54.45 \pm 14.42$ & $71.99 \pm 14.16$ & -8.999 & $0.000^{* *}$ \\
Social function & $56.81 \pm 11.08$ & $69.93 \pm 11.55$ & -8.522 & $0.000^{* *}$ \\
\hline
\end{tabular}

${ }^{* *} \mathrm{p}<0.01$.

\subsection{The Frequency and Characteristics of the Quality of Life of Respondents in four Dimension}

Material condition: It can be inferred from Table 3 that the score of material condition is $(51.65 \pm 14.45)$, which is the lowest one in the four of the quality of life. Through statistical analysis of the frequency of the score in material condition, it is clear that the score in material condition is large-span, that approximately $70 \%$ is lower than 60 , indicating that the majority of them is at a medium or low level. More details are shown in Figure 2. In addition, the order of four factors in the material condition from high to low is housing, living environment, economic status, and community service, which are far below that of control group. The difference is statistically significant. More details are shown in Table 4.

Physical function: It can be inferred from Table 3 that the score of physical function is $(57.51 \pm 13.30)$, which is the highest one in the four dimensions. We 
can find out that the score in physical function ranges between 45 and 65 through statistical analysis of the frequency of the scores in physical function. More details are shown in Figure 3. In addition, the order of five factors in physical function from high to low is movement and sense function, eating function, somatic discomfort, sexual function, sleep and energy, which are far below that of control group. The difference is statistically significant. More details are shown in Table 5.

Psychological function: It can be inferred from Table 3 that the score of psychological function is $(54.45 \pm 14.42)$. Through statistical analysis of the frequency of the scores in psychological function, it is clear that the score in psychological function is large-span, that nearly $50 \%$ ranges between 45 and 60 . More details are shown in Figure 4. In addition, the order of five factors in psychological function from high to low is nervousness, negative emotion, self-esteem, cognitive function, positive emotion, which are far below that of control group. The difference is statistically significant. More details are shown in Table 6.

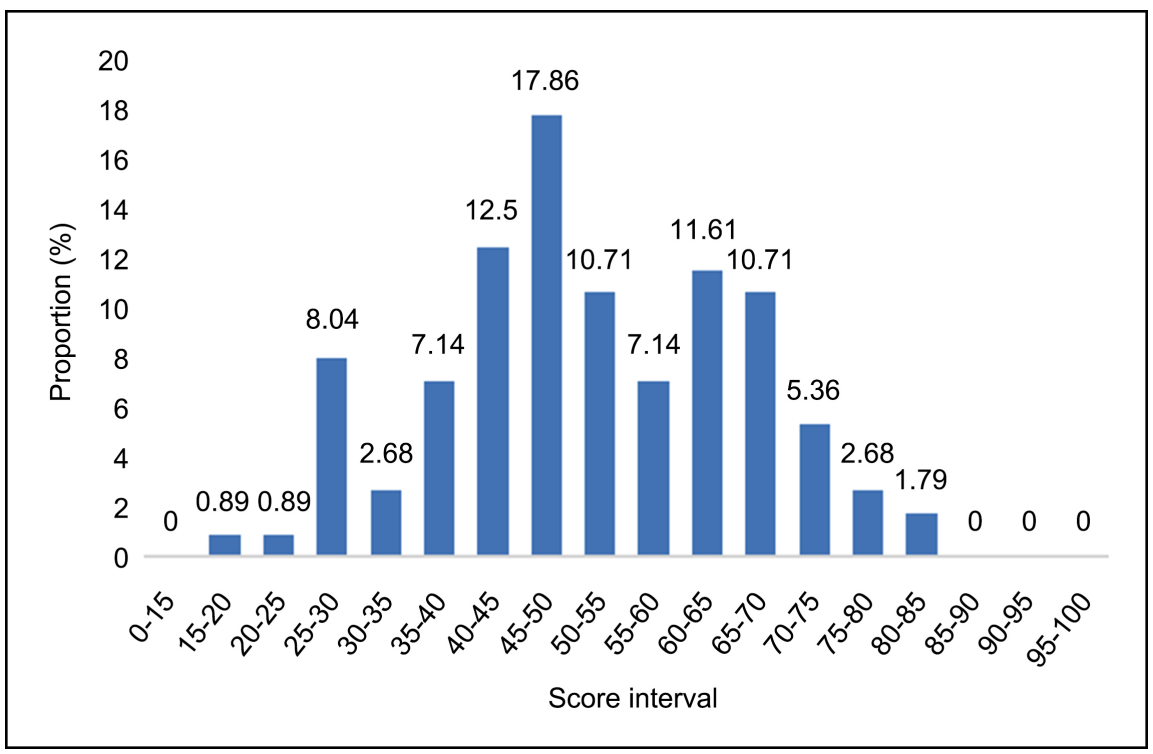

Figure 2. Frequency graph of scores in material condition. Note: The score interval does not include the small value, for example, the 0 to 15 range $(\mathrm{X})$ refers to $0<\mathrm{X} \leq 15$.

Table 4. The scores and difference test of material condition and its factors $(\bar{x} \pm s)$.

\begin{tabular}{ccccc}
\hline & Case group & Control group & $\mathbf{t}$ & $\mathbf{p}$ \\
\hline Material condition & $51.65 \pm 14.45$ & $72.2 \pm 13.23$ & -10.907 & $0.000^{* *}$ \\
Housing & $64.40 \pm 19.78$ & $82.93 \pm 13.13$ & -8.050 & $0.000^{* *}$ \\
Community service & $42.80 \pm 19.73$ & $69.17 \pm 21.59$ & -9.380 & $0.000^{* *}$ \\
Living environment & $53.64 \pm 18.93$ & $72.52 \pm 17.02$ & -7.687 & $0.000^{* *}$ \\
Economical status & $45.76 \pm 15.48$ & $64.40 \pm 15.58$ & -8.817 & $0.000^{* *}$ \\
\hline
\end{tabular}

${ }^{* *} \mathrm{p}<0.01$ 
Table 5. The scores and difference test of physical function and its factors $(\bar{x} \pm s)$.

\begin{tabular}{ccccc}
\hline & Case group & Control group & $\mathrm{t}$ & $\mathrm{p}$ \\
\hline Physical function & $57.51 \pm 13.30$ & $74.33 \pm 11.58$ & -9.874 & $0.000^{* *}$ \\
Sleep and energy & $46.79 \pm 18.98$ & $66.59 \pm 14.70$ & -8.524 & $0.000^{* *}$ \\
Somatic discomfort & $59.30 \pm 17.42$ & $76.20 \pm 14.29$ & -7.762 & $0.000^{* *}$ \\
Eating function & $62.00 \pm 16.76$ & $76.74 \pm 13.59$ & -7.069 & $0.000^{* *}$ \\
Sexual function & $50.06 \pm 19.60$ & $70.79 \pm 21.25$ & -7.462 & $0.000^{* *}$ \\
Movement and sense function & $69.42 \pm 14.92$ & $81.31 \pm 12.98$ & -6.229 & $0.000^{* *}$ \\
\hline
\end{tabular}

${ }^{* *} \mathrm{p}<0.01$.

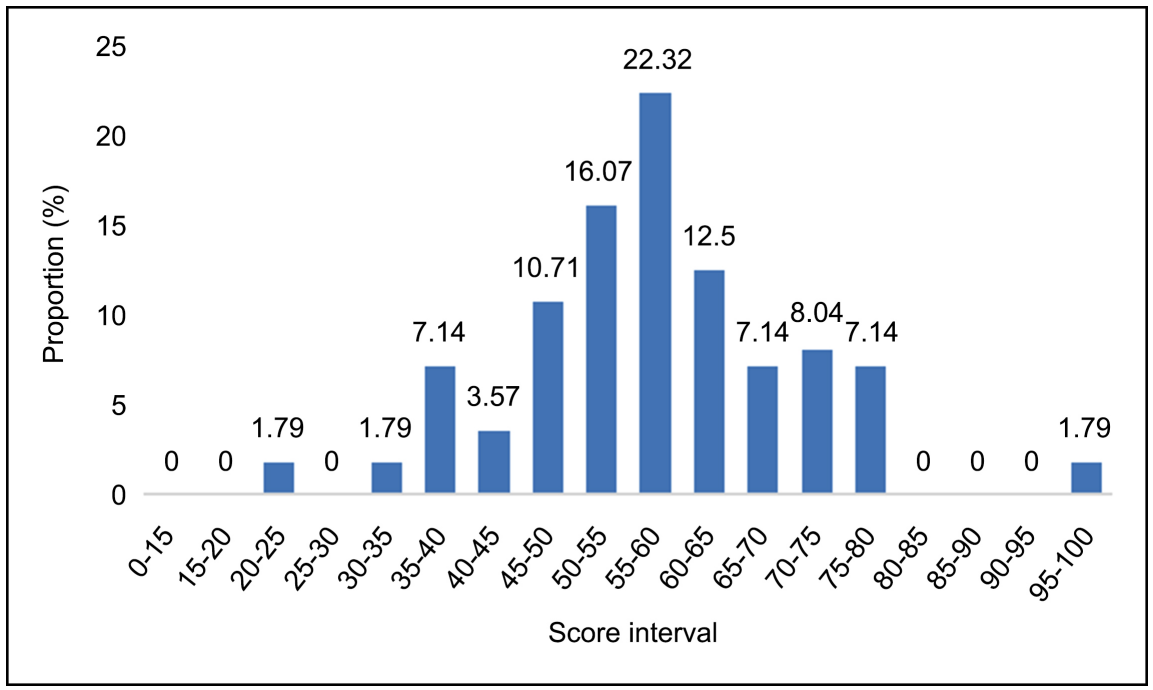

Figure 3. Frequency graph of scores in physical function. Note: The score interval does not include the small value, for example, the 0 to 15 range $(\mathrm{X})$ refers to $0<\mathrm{X} \leq 15$.

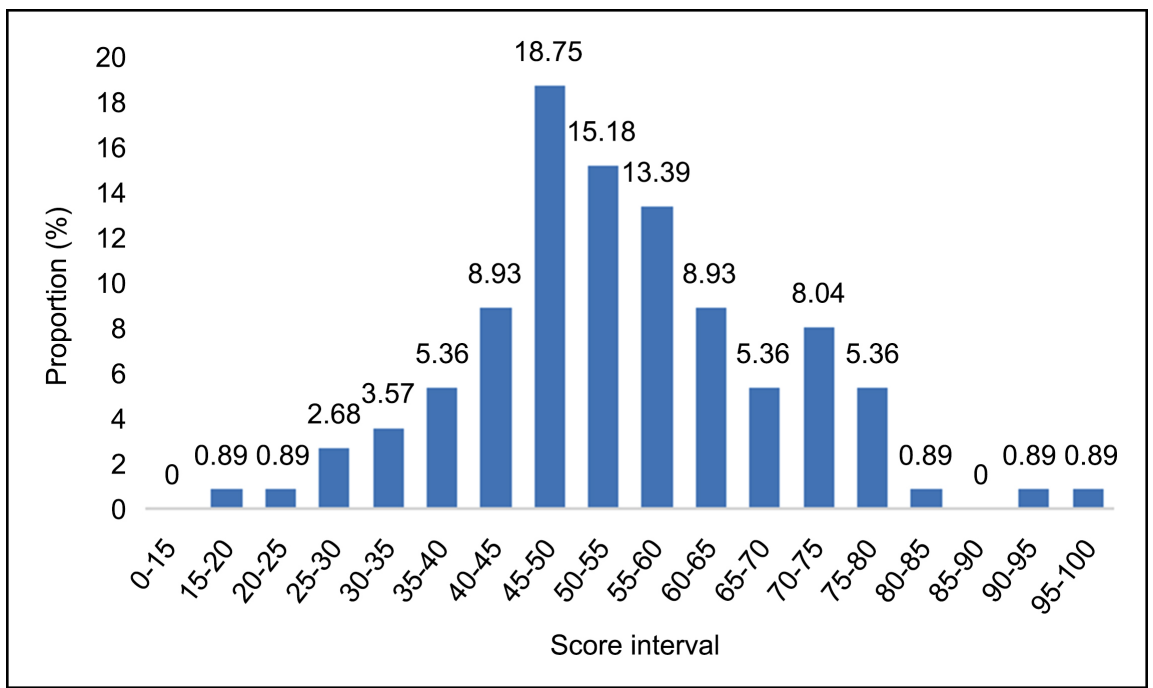

Figure 4. Frequency graph of scores in psychological function. Note: The score interval does not include the small value, for example, the 0 to 15 range $(\mathrm{X})$ refers to $0<\mathrm{X} \leq 15$. 
Table 6. The scores and difference test of psychological function and its factors $(\bar{x} \pm s)$.

\begin{tabular}{ccccc}
\hline & Case group & Control group & $\mathrm{t}$ & $\mathrm{p}$ \\
\hline Psychological function & $54.45 \pm 14.42$ & $71.99 \pm 14.16$ & -8.999 & $0.000^{* *}$ \\
Nervousness & $56.21 \pm 17.77$ & $76.52 \pm 17.91$ & -8.363 & $0.000^{* *}$ \\
Negative function & $55.52 \pm 18.77$ & $76.14 \pm 16.56$ & -8.532 & $0.000^{* *}$ \\
Positive emotion & $50.78 \pm 19.70$ & $69.65 \pm 18.83$ & -7.186 & $0.000^{* *}$ \\
Cognitive function & $54.77 \pm 17.02$ & $69.38 \pm 16.95$ & -6.317 & $0.000^{* *}$ \\
Self-esteem & $55.08 \pm 13.25$ & $68.27 \pm 14.51$ & -6.982 & $0.000^{* *}$ \\
\hline
\end{tabular}

${ }^{* *} \mathrm{p}<0.01$.

Social function: It can be inferred from Table 3 that the score of social function is $(56.81 \pm 11.08)$. It is clear that over $70 \%$ ranges between 45 and 65 through statistical analysis of the frequency of the scores in social function. More details are shown in Figure 5. In addition, the order of five factors in social function from high to low is interpersonal skill, marriage and family, learning and working, social suspport, entertainment life, which are far below that of control group. The difference is statistically significant. More details are shown in Table 7.

\subsection{The Influence of Demographic Variables on Caregivers' Quality of life}

\subsubsection{Demographic Variables that Have No Effect on Caregivers' Quality of Life}

We performed one-way analysis of variance in caregivers' family role, age, children's age, degree of intellectual disability, the number of children, marital status of children's parents and annual rehabilitation costs, and there is no significant difference in caregivers' quality of life in caregivers' family role, age, children's age, degree of intellectual disability, the number of children, marital status of children's parents and annual rehabilitation costs. Meanwhile, we performed t-test for independent sample in children's gender, and there is no significant difference in caregivers' quality of life in children's gender.

\subsubsection{Demographic Variables that Affect Parents' Quality of Life}

Home address: The scores of quality of life and of four dimensions of respondents with different home addresses are shown in Table 8. We performed one-way analysis of variance in home address, and the results show that home address is statistically different in material condition $(\mathrm{P}=0.001<0.05)$. Through Fisher's least significant difference $t$ test, we discover that the material condition of respondents living in the township or the country is worse than that living in the downtown. However, there is no statistical significance in quality of life, physical function, psychological function and social function caused by home address. 


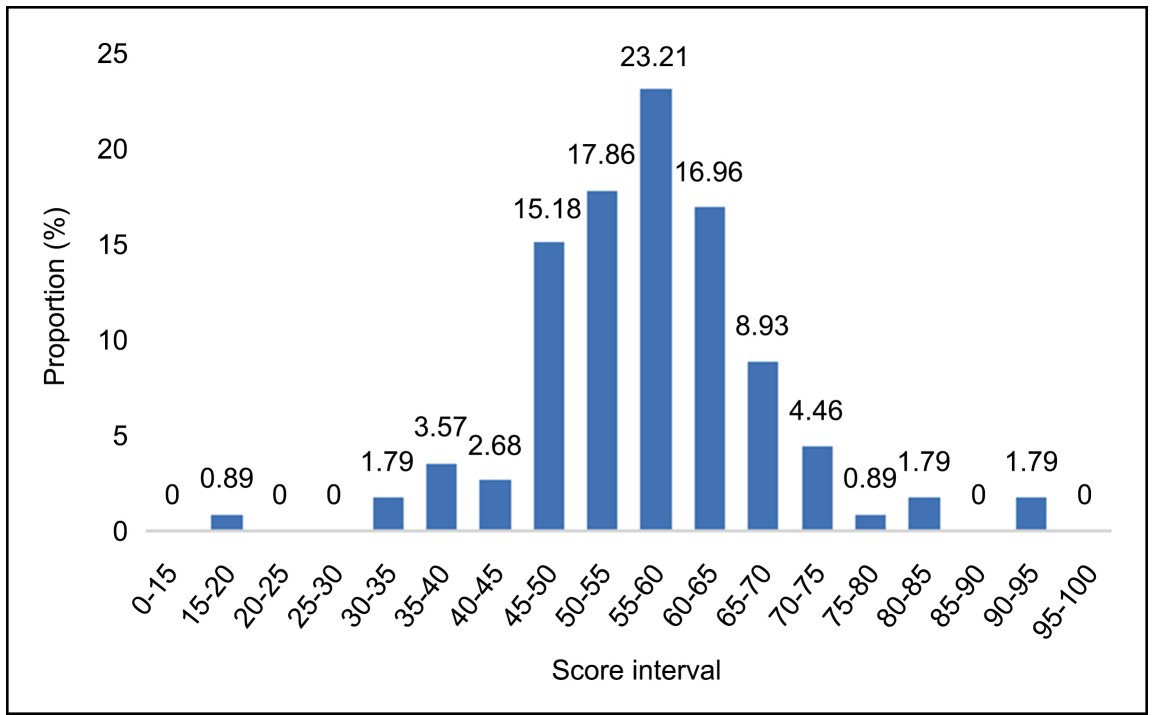

Figure 5. Frequency graph of scores in social function. Note: The score interval does not include the small value, for example, the 0 to 15 range $(\mathrm{X})$ refers to $0<\mathrm{X} \leq 15$.

Table 7. The scores and difference test of social function dimension and its factors $(\bar{x} \pm s)$.

\begin{tabular}{ccccc}
\hline & Case group & Control group & $\mathrm{t}$ & $\mathrm{p}$ \\
\hline Social function & $56.81 \pm 11.08$ & $69.93 \pm 11.55$ & -8.522 & $0.000^{* *}$ \\
Social support & $51.44 \pm 17.07$ & $69.39 \pm 17.36$ & -7.660 & $0.000^{* *}$ \\
Interpersonal skill & $66.27 \pm 15.04$ & $77.91 \pm 12.67$ & -6.132 & $0.000^{* *}$ \\
Learning and working & $54.46 \pm 13.29$ & $67.55 \pm 14.15$ & -7.007 & $0.000^{* *}$ \\
Entertainment life & $48.80 \pm 19.26$ & $57.72 \pm 15.46$ & -3.737 & $0.000^{* *}$ \\
Marriage and family & $63.06 \pm 14.05$ & $77.07 \pm 15.24$ & -7.033 & $0.000^{* *}$ \\
\hline
\end{tabular}

${ }^{* *} \mathrm{p}<0.01$.

Table 8. Comparisons of scores of quality of life and its dimensions on home address $(\bar{x} \pm s)$.

\begin{tabular}{|c|c|c|c|c|c|}
\hline & Total & $\begin{array}{l}\text { Material } \\
\text { condition }\end{array}$ & $\begin{array}{l}\text { Physical } \\
\text { function }\end{array}$ & $\begin{array}{l}\text { Psychological } \\
\text { function }\end{array}$ & $\begin{array}{c}\text { Social } \\
\text { function }\end{array}$ \\
\hline Downtown $^{(1)}$ & $56.73 \pm 10.10$ & $56.20 \pm 13.55$ & $58.19 \pm 12.40$ & $55.63 \pm 12.62$ & $57.74 \pm 10.31$ \\
\hline Township $^{(2)}$ & $51.67 \pm 14.08$ & $47.47 \pm 17.16$ & $53.08 \pm 15.78$ & $50.35 \pm 17.68$ & $53.88 \pm 13.02$ \\
\hline Countryside $^{3}$ & $54.42 \pm 10.05$ & $46.05 \pm 11.62$ & $58.98 \pm 13.12$ & $54.91 \pm 15.30$ & $56.90 \pm 11.21$ \\
\hline $\mathbf{F}$ & 1.841 & 6.909 & 1.397 & 1.019 & 0.906 \\
\hline $\mathbf{P}$ & 0.163 & $0.001^{\star *}$ & 0.252 & 0.364 & 0.407 \\
\hline LSD & & (1) $>$ (2)/3) & & & \\
\hline
\end{tabular}

Note: ${ }^{* *} \mathrm{p}<0.01$ 
Occupation of children's parents: Table 9 presents their scores of quality of life and of four dimensions influenced by occupation of children's parents. We performed one-way analysis of variance in father's occupation, and the results show that father's occupation is statistically different in social function $(\mathrm{P}=$ $0.015<0.05)$. Through Fishers least significant difference $t$ test, we discover that social function of father who is self-employed or freelancer is better than that takes other job or is unemployed. Similar analysis was performed in mother's occupation, then we find out that there is no significant difference in their quality of life caused by mother's occupation.

Education level of children's parents: Table 10 presents their scores of quality of life and of four dimensions influenced by education level of children's parents. We performed one-way analysis of variance in father's education level, and in mother's education level, respectively. The results show that father's education level is statistically different in material condition $(\mathrm{P}=0.004<0.01)$ and psychological function $(\mathrm{P}=0.026<0.05)$, while mother's education level is not. Through Fishers least significant difference $t$ test, we discover that material condition of father whose education level is master or above is better than that is

Table 9. Comparisons of scores of quality of life and its dimensions on parents' occupation $(\bar{x} \pm s)$.

\begin{tabular}{|c|c|c|c|c|c|}
\hline & Total & $\begin{array}{l}\text { Material } \\
\text { condition }\end{array}$ & $\begin{array}{l}\text { Physical } \\
\text { function }\end{array}$ & $\begin{array}{l}\text { Psychological } \\
\text { function }\end{array}$ & $\begin{array}{c}\text { Social } \\
\text { function }\end{array}$ \\
\hline \multicolumn{6}{|l|}{ Father } \\
\hline Self-employed or freelancer ${ }^{(1)}$ & $61.14 \pm 12.03$ & $55.20 \pm 17.65$ & $61.57 \pm 12.21$ & $62.16 \pm 18.26$ & $64.63 \pm 12.24$ \\
\hline $\begin{array}{l}\text { Worker in enterprise and } \\
\text { public institution }\end{array}$ & $54.29 \pm 10.64$ & $52.13 \pm 13.31$ & $56.42 \pm 13.23$ & $53.50 \pm 13.07$ & $55.63 \pm 10.13$ \\
\hline Farmer $^{3}$ & $52.81 \pm 11.45$ & $43.99 \pm 14.33$ & $56.90 \pm 16.64$ & $53.43 \pm 12.24$ & $55.46 \pm 11.65$ \\
\hline Unemployed $^{(4}$ & $53.26 \pm 9.27$ & $49.14 \pm 16.15$ & $59.22 \pm 13.02$ & $50.10 \pm 16.20$ & $53.83 \pm 11.44$ \\
\hline $\mathrm{F}$ & 2.158 & 1.336 & 0.759 & 2.139 & 3.662 \\
\hline $\mathbf{P}$ & 0.097 & 0.267 & 0.520 & 0.099 & $0.015^{*}$ \\
\hline LSD & & & & & (1) $>$ (2)/(3)/(4) \\
\hline \multicolumn{6}{|l|}{ Mother } \\
\hline Self-employed or freelancer ${ }^{(1)}$ & $61.76 \pm 12.60$ & $58.67 \pm 13.95$ & $61.99 \pm 13.99$ & $63.42 \pm 17.51$ & $62.58 \pm 15.47$ \\
\hline $\begin{array}{l}\text { Worker in enterprise and } \\
\text { public institution }{ }^{2}\end{array}$ & $55.80 \pm 10.31$ & $53.26 \pm 14.17$ & $57.66 \pm 11.80$ & $54.69 \pm 13.22$ & $57.72 \pm 9.76$ \\
\hline Farmer $^{(3)}$ & $52.48 \pm 0.63$ & $47.83 \pm 9.47$ & $53.52 \pm 17.79$ & $54.13 \pm 11.92$ & $53.77 \pm 10.61$ \\
\hline Unemployed $^{(4)}$ & $53.23 \pm 10.68$ & $49.11 \pm 15.27$ & $57.07 \pm 13.32$ & $51.84 \pm 14.51$ & $55.07 \pm 10.56$ \\
\hline F & 2.398 & 1.978 & 0.835 & 2.258 & 1.974 \\
\hline $\mathbf{P}$ & 0.072 & 0.122 & 0.477 & 0.086 & 0.122 \\
\hline
\end{tabular}

Note: ${ }^{* *} \mathrm{p}<0.01$. 
Table 10. Comparisons of scores of quality of life and its dimensions on parents' education level $(\bar{x} \pm s)$.

\begin{tabular}{|c|c|c|c|c|c|}
\hline & Total & $\begin{array}{l}\text { Material } \\
\text { condition }\end{array}$ & $\begin{array}{l}\text { Physical } \\
\text { function }\end{array}$ & $\begin{array}{l}\text { Psychological } \\
\text { function }\end{array}$ & $\begin{array}{c}\text { Social } \\
\text { function }\end{array}$ \\
\hline \multicolumn{6}{|l|}{ Father } \\
\hline Master or above ${ }^{(\mathbb{1}}$ & $61.11 \pm 7.96$ & $64.02 \pm 10.06$ & $61.50 \pm 8.02$ & $59.86 \pm 13.06$ & $59.76 \pm 6.10$ \\
\hline Undergraduate $^{(2)}$ & $55.88 \pm 11.91$ & $55.73 \pm 14.07$ & $57.94 \pm 14.00$ & $54.39 \pm 14.23$ & $56.61 \pm 12.06$ \\
\hline High school ${ }^{3}$ & $50.56 \pm 9.57$ & $45.61 \pm 11.34$ & $52.53 \pm 10.18$ & $48.48 \pm 13.21$ & $55.00 \pm 10.92$ \\
\hline Middle school $^{(4)}$ & $55.07 \pm 10.34$ & $48.11 \pm 15.51$ & $58.90 \pm 15.51$ & $55.39 \pm 12.87$ & $56.91 \pm 8.61$ \\
\hline Elementary or below ${ }^{(5)}$ & $60.43 \pm 9.54$ & $47.45 \pm 13.45$ & $62.92 \pm 9.34$ & $67.47 \pm 19.01$ & $61.40 \pm 16.64$ \\
\hline $\mathrm{F}$ & 2.024 & 4.062 & 1.371 & 2.876 & 0.561 \\
\hline $\mathbf{P}$ & 0.096 & $0.004^{\star *}$ & 0.249 & $0.026^{*}$ & 0.691 \\
\hline LSD & & $\begin{array}{c}(1)>(3) / 4 /(5) \\
(2)>\text { (3)/(4) }\end{array}$ & & (5) $>$ (2)/(3//4) & \\
\hline \multicolumn{6}{|l|}{ Mother } \\
\hline Master or above & $64.05 \pm 11.51$ & $68.56 \pm 3.03$ & $65.94 \pm 11.94$ & $62.09 \pm 22.39$ & $60.83 \pm 10.61$ \\
\hline Undergraduate & $54.27 \pm 11.76$ & $53.18 \pm 14.14$ & $56.68 \pm 13.84$ & $52.43 \pm 14.70$ & $55.56 \pm 11.68$ \\
\hline High school & $56.27 \pm 10.53$ & $53.03 \pm 14.50$ & $58.53 \pm 12.18$ & $55.92 \pm 13.23$ & $58.06 \pm 10.39$ \\
\hline Middle school & $54.56 \pm 9.52$ & $47.53 \pm 15.03$ & $56.58 \pm 13.14$ & $55.48 \pm 12.40$ & $57.49 \pm 9.05$ \\
\hline Elementary or below & $58.00 \pm 12.44$ & $49.47 \pm 12.78$ & $62.24 \pm 14.27$ & $59.35 \pm 21.05$ & $58.83 \pm 16.42$ \\
\hline $\mathrm{F}$ & 0.611 & 1.564 & 0.560 & 0.713 & 0.381 \\
\hline $\mathbf{P}$ & 0.655 & 0.189 & 0.692 & 0.585 & 0.822 \\
\hline
\end{tabular}

Note: ${ }^{*} \mathrm{p}<0.05 ;{ }^{* *} \mathrm{p}<0.01$.

high school, middle school and elementary or below, that material condition of father whose education level is high school is better than that is middle school and elementary or below, that psychological function of father whose education level is elementary or below is better than that is undergraduate, high school and middle school.

Family's annual income: Table 11 shows their scores of quality of life and of four dimension influenced by family's annual income. We performed one-way analysis of variance in family's annual income, and the results show that family's annual income is statistically different in their quality of life $(\mathrm{P}=0.009<0.01)$ and in material condition $(\mathrm{P}=0.000<0.01)$. Through Fishers least significant difference $t$ test, we discover that their quality of life of families with annual income over 80,000 is higher than that below 80,000 , that their material condition of families with annual income over 80,000 is higher than that below it and their material condition of families with annual income of 30,000 to 80,000 is higher 
than that below 30,000. There is no significant difference in physical function, psychological function and social function caused by family's annual income.

Correlation analysis between basic demographic variables and respondents' quality of life: Pearson correlation analysis is performed on the basic demographic variables and respondents' scores of quality of life and of its dimensions to further determine whether the basic demographic variables their quality of life, and the results are shown in Table 12. Family's annual income is positively correlated with their scores of quality of life, of material condition and of social function; home address ( $1=$ country, $2=$ township, $3=$ downtown $)$ and father's education level $(1=$ elementary or below, $2=$ middle school, $3=$ high school, $4=$ undergraduate, $5=$ master or above) are positively correlated with their scores of material life; father's occupation ( $1=$ unemployed, $2=$ farmer, $3=$ worker in enterprise and public institution, $4=$ self-employed or freelancer) is positively correlated with their scores of psychological function and of social function.

Table 11. Comparisons of scores of quality of life and its dimensions on family's annual income ( $\bar{x} \pm s)$.

\begin{tabular}{|c|c|c|c|c|c|}
\hline & Total & $\begin{array}{l}\text { Material } \\
\text { condition }\end{array}$ & $\begin{array}{l}\text { Physical } \\
\text { function }\end{array}$ & $\begin{array}{l}\text { Psychological } \\
\text { function }\end{array}$ & $\begin{array}{c}\text { Social } \\
\text { function }\end{array}$ \\
\hline $\mathrm{z} \leq 30,000^{(1)}$ & $52.56 \pm 11.13$ & $43.99 \pm 15.14$ & $56.37 \pm 13.93$ & $53.89 \pm 15.54$ & $54.65 \pm 11.42$ \\
\hline $30,000<\mathrm{z} \leq 80,000^{(2)}$ & $53.51 \pm 8.96$ & $50.85 \pm 10.90$ & $55.74 \pm 11.50$ & $51.90 \pm 12.44$ & $55.77 \pm 10.62$ \\
\hline $80,000<z \leq 300,000^{3}$ & $59.80 \pm 12.49$ & $60.42 \pm 13.78$ & $60.58 \pm 15.23$ & $58.55 \pm 15.56$ & $60.76 \pm 11.22$ \\
\hline$z>300,000^{(4)}$ & $67.03 \pm 7.97$ & $69.97 \pm 8.40$ & $71.39 \pm 4.09$ & $66.32 \pm 14.77$ & $61.94 \pm 5.72$ \\
\hline $\mathrm{F}$ & 4.081 & 10.043 & 1.988 & 1.985 & 1.968 \\
\hline $\mathbf{P}$ & $0.009^{*}$ & $0.000^{* *}$ & 0.120 & 0.121 & 0.123 \\
\hline LSD & $\begin{array}{l}\text { (3) > } 1 / /(2) \\
\text { (4) > } 1 / /(2)\end{array}$ & $\begin{array}{c}(4) /(3) /(2)>1 \\
\text { (4) } /(3)>\text { (2) }\end{array}$ & & & \\
\hline
\end{tabular}

Note: ${ }^{*} \mathrm{p}<0.05 ;{ }^{* *} \mathrm{p}<0.01$

Table 12. Correlation between basic demographic variables and parents' quality of life and its four dimensions $(\gamma)$.

\begin{tabular}{|c|c|c|c|c|}
\hline & Home address & Father's occupation & $\begin{array}{c}\text { Father's education } \\
\text { level }\end{array}$ & $\begin{array}{l}\text { Family's annual } \\
\text { income }\end{array}$ \\
\hline Quality of life & 0.111 & 0.172 & 0.028 & $0.288^{* *}$ \\
\hline Material condition & $0.321^{\star *}$ & 0.147 & $0.294^{* *}$ & $0.464^{* *}$ \\
\hline Physical function & -0.006 & 0.032 & -0.029 & 0.171 \\
\hline Psychological function & 0.038 & $0.188^{*}$ & -0.086 & 0.155 \\
\hline Social function & 0.048 & $0.218^{*}$ & -0.032 & $0.211^{*}$ \\
\hline
\end{tabular}

Note: ${ }^{* *} \mathrm{p}<0.01 ;{ }^{*} \mathrm{p}<0.05$. 


\section{Discussion}

\subsection{Characteristics of Quality of Life and Its Dimensions of Respondents}

The investigation shows that their scores of quality of life are large-span, indicating that their quality of life varies widely, which may be caused by their personality, such as family background and employment background, and approximately $70 \%$ of them range from 45 to 65 . From the perspective of their quality of life, the physical function has the highest score, followed by the social function, the psychological function and the material condition, while the scores of control group in the same area rank from the highest to the lowest in order of physical function, material condition, psychological function and social function, which indicates that mentally retarded children break their caregivers' normal state of material condition, psychological function and social interaction, especially the material condition, which may be caused by a large amount of rehabilitation costs, which undoubtedly reduced other household expenses.

Material condition scores the lowest among four dimensions, manifesting that they have poor material conditions. The reasons may be that the rehabilitation expenses of mentally retarded children were high in China and at least one person gives up work to take care of child's rehabilitation training and daily life in most families, so their family income declines. As Hu Xiaoyi pointed out, the proportion of parents of special children without work is high, and the unemployment rate is higher than other group [13] [14]. Hence, the huge contradiction between income and expenditure makes parents have to adjust the allocation of limited economic resources and reduce the economic expenses for non-daily necessities, which is proved by scores of four factors in material condition-the community service scores lowest in the material condition, reflecting they are unable to pay for the cost of non-essential services due to financial constraints.

Physical function scores the highest among four dimensions, indicating that they are in good health. The reason may be that the respondents are mostly the parents of the children, and most of them are in their prime time $(<50$ years old), therefore their physical function is in the golden age, which is proved by scores of five factors in physical function. The scores of these factors rank from the highest to the lowest in order of movement and sense function, eating function, somatic discomfort, sexual function, sleep and energy. On account of this we can discover that they have good physical function, movement and sense function and eating function, and they spend most of their time and energy to take care of mentally retarded children, therefore their sleep health and sexual function deserve more attention.

Psychological function dimension ranks third in the four dimensions. Half of their scores range from 45 to 60 , manifesting that they have poor psychological function. Parenting an individual with intellectual disabilities can be challenging [15] and have negative impact on them. Meanwhile, their scores are large-span, 
indicating that their psychological functions vary widely, which may be related to their psychological adjustment ability, family's support, etc. Thought the experience of parenting a child with intellectual disabilities can be fraught with self-criticism, isolation, and rare opportunities for self-care or mindfulness [16], a previous study proved that greater self-compassion, a psychological state defined as "awareness of one's suffering and shortcomings rather than rumination or avoidance", was related to lower levels of stress and depression [17]. In addition, the positive emotion scores lowest in psychological function, which indicates that they generate great psychological pressure and more negative emotions because of mentally retarded children.

The score of social function ranks second in four dimensions. One reason is that their great psychological and material pressure can be relieved through interpersonal communication. Social support comes from people's social contact, namely interpersonal communication, and it can attenuate the relationship between caring for individuals with intellectual disabilities and parent-related stress [18]. Furthermore, the scores of five factors rank from the highest to the lowest in order of "interpersonal skill", "marriage and family", "learning and working", "social support" and "entertainment life", which means that their interpersonal communication is good. Their entertainment life scores the lowest, reflecting they spend most of their time in looking after mentally retarded children and lack of time for entertainment. Similarly, a previous study showed that parents raising mentally retarded children spend more time on "domestic work" and "care and supervision" and spend on average $1.5 \mathrm{~h}$ per day less on free activities than parents raising typically developing children [19]. However, participation in leisure activities has been identified as a coping strategy for day-to-day stress [20] and contributes to people's well-being [21].

\subsection{The Difference Analysis of Their Quality of Life and Its Dimensions based on Demographic Variables}

The results of this research show that there is no significant difference in their scores from GQOLI-74 caused by children's gender, age, degree of intellectual disability, the number of children, family roles, age, marital status of children's parents, home address, occupation of children's parents, education level of children's parents, and rehabilitation costs, indicating that these are not major influence factors on their quality of life. That is to say, mentally retarded children have an impact on respondents' quality of life regardless of children's condition, respondents' family background, occupation of children's parents and education level of children's parents, which can be supported by Thomas study: a family is an interdependent unit, and what happens to one member of the unit has an impact on other members [22]. However, there is significant difference in their quality of life caused by family's annual income, manifesting that family's annual income is closely related to their quality of life. Through Fishers least significant difference $t$ test, we discover that the lower family's annual income is, 
the worse quality of life they have. Similarly, other studies demonstrated that the level of income of the family decreased, the family burden, and especially the economic burden, correspondingly increased [23]. For individuals with good socio-economic status, they are more likely to seek and receive better support materially [24]. That is to say: for those who with higher family's annual incomes, they usually have better financial capacity to face difficulties. Even if rehabilitation costs are high, they can maintain original living conditions, thus ensuring that their living standards are not excessively declined.

More significantly, there is statistical significance in some dimensions of their quality of life caused by home address, family's annual income, father's occupation and father's education level. To start with, there is significant difference in material condition caused by home address and family's annual income. Through Fishers least significant difference $t$ test, we discover that some of them living in downtown score higher than those living in township or in country in material condition dimension; that the higher the family's annual income, the higher the material life score. The difference in material condition caused by home address may have something to do with the huge gap between China's urban and rural areas and the city's "dualization" structure nowadays, especially the huge income gap among downtown, township and country. Furthermore, there is significant difference in social function caused by father's occupation. Through Fishers least significant difference $t$ test, we discover that he who is self-employed or freelancer scores higher than that who is taking other job or unemployed, the reason of which may be that he who is self-employed or freelancer has strong controllability in time, has greater possibility and space in income, and needs more social interaction to promote career's development, thus his social function is relatively good. Ultimately, there is significant difference in material condition and psychological function caused by father's education level. Through Fishers least significant difference $t$ test, we discover that the higher the education level of the father, the better the material living conditions, which is mainly caused by the fact that people with higher education level usually get higher-earning jobs. While mother's education level has no effect on the material conditions, which may be due to mothers giving up their jobs to care for their children full-time. Similarly, the previous studies showed that a mentally retarded child can cause stress for the parents especially for the mother who is responsible for the child's parenting [25], hence having a child with intellectual disability is an indirect reason why many mothers have left the labour market [26] or have been underemployed [27]. Moreover, the more highly educated the mothers are, the more likely to be involuntarily underemployed [27], which reveals highly educated mothers are willing to work rather than take care of mentally retarded kids only. Furthermore, we discover that the psychological function of father whose education level is elementary or below works better than that is undergraduate, middle school and high school through Fishers least significant difference $t$ test. However, the previous studies showed just the opposite, 
and have demonstrated that individuals with better education are more likely to have better awareness of the situation and to seek and receive better support psychologically to decrease their psychological distress [24] [28]. That's to say, better education were associated with less psychological distress. One reason of our different result may be that for serious stigma of "intellectual disabilities" and deep-rooted "face-saving" in China, it is more difficult for fathers with higher education to accept the fact that their children are "mentally retarded". A previous study demonstrated that parents experience stigma and discrimination in their daily life [29]. At the same time, they don't see an obvious improvement of child after much money and time paid for rehabilitation, which brings on more negative emotions.

\section{Conclusion}

There is enormous economic and mental stress on respondents from rehabilitation training and daily care of mentally retarded children, affecting their work, rest and social activity, so that their quality of life is not high, which is far below the quality of life of control group. Therefore, paying attention to quality of life of caregivers of mentally retarded children is an all-important and indispensable task, which not only involves the quality of life of caregivers, but also affects the rehabilitation training and living standards of mentally retarded children, so this research reveals the caregivers' low quality of life, and analyzes the reasons that affect their quality of life, so as to improve their quality of life.

\section{Conflicts of Interest}

The authors declare no conflicts of interest regarding the publication of this paper.

\section{References}

[1] Xinhua News Agency (2014) Pay Special Attention to Groups of People with Disabilities. http://politics.people.com.cn/n/2014/0322/c70731-24705779.html

[2] World Health Organization (n.d.) Disability and Health. http://www.who.int/mediacentre/factsheets/fs352/en/

[3] Zhao, Y.C. (2012) China Disabled Persons' Federation Released the Latest Data on the Disabled Population in China. Disability in China, 4, 20.

[4] CCTV Network (2016) China Disabled Persons' Federation: Over 1.67 Million Disabled Children in China and about 200,000 Newly Added Each Year. http://news.cctv.com/2016/08/31/ARTIVFbRwS4E3qSxedX2b6KV160831.shtml

[5] Li, X.H. (2018) The Influence of Autistic Children on Families and the Coping Strategies: An Understanding Framework Based on Literature Review. Social Work and Management, 18, 34-39.

[6] Karayagiz, M.G. and Coskun, C.S. (2018) The Family Burdens and Hopelessness of Turkish Parents of Adolescents with Intellectual Disabilities. Rehabilitation Nursing, 43, 351-362.

[7] Learning Power Platform (2019) Xi Jinping Made Important Instructions on Civil 
Affairs.

https://article.xuexi.cn/html/9351406259409176181.html?study comment disable= 0\&study style $\mathrm{id}=$ feeAugustds default\&source $=$ share\&share to $=\mathrm{wx}$ single\&from $=$ $\underline{\text { singlemessage\&isappinstalled }=0}$

[8] People's Daily Online (2018) A Well-Off Society Will Be Completely Built in 2020, Every Disabled People Included. http://gongyi.people.com.cn/n1/2018/0521/c151132-30002276.html

[9] Hu, X.Y. (2016) Family Quality of Life and Family Support of Children with Disabilities in China. Chinese Journal of Rehabilitation Theory and Practice, 10, 1227-1231.

[10] Li, L.J., Hao, W., Yang, D.S., Zhang, Y.L., Wu, G., Luo, Y.G., Huang, J., Zhang, B., Liu, J.N. and Liao, J.F. (1995) Study on Quality of Life of General Population in Hunan Province: IV. Development of Quality of Life Inventory. Chinese Mental Health Journal, 227-231, 239, 236.

[11] Wang, L., Li, L.J., Jiang, H.B., Yu, J.H., Fang, J. and Yang, D.S. (1997) A Comparative Study on the Quality of Life of the Caregivers of Hypertension Patients. Chinese Journal of Behavioral Medical Science, 4, 265-268.

[12] Li, L.J., Yang, D.S., Hu, Z.P. and Wen, F. (1997) Development of Quality of Life Inventory for Cerebral Apoplexy Patients. Chinese Journal of Behavioral Medicine and Brain Science, 1, 6-9.

[13] Hu, X.Y. and Wang, M. (2012) On the Life Quality of Families with Children with Developmental Disabilities in Beijing. Chinese Journal of Special Education, 7, 3-10, 29.

[14] Rillotta, F., Kirby, N., Shearer, J. and Nettelbeck, T. (2012) Family Quality of Life of Australian Families with a Member with an Intellectual/Developmental Disability. Journal of Intellectual Disability Research, 56, 71-86. https://doi.org/10.1111/j.1365-2788.2011.01462.x

[15] Davis, N.O. and Carter, A.S. (2008) Parenting Stress in Mothers and Fathers of Toddlers with Autism Spectrum Disorders: Associations with Child Characteristics. Journal of Autism and Developmental Disorders, 38, 1278-1291. https://doi.org/10.1007/s10803-007-0512-z

[16] Vasilopoulou, E. and Nisbet, J. (2016) The Quality of Life of Parents of Children with Autism Spectrum Disorder: A Systematic Review. Research in Autism Spectrum Disorders, 23, 36-49. https://doi.org/10.1016/j.rasd.2015.11.008

[17] Robinson, S., Hastings, R.P., Weiss, J.A., Pagavathsing, J. and Lunsky, Y. (2018) Self-Compassion and Psychological Distress in Parents of Young People and Adults with Intellectual and Developmental Disabilities. Journal of Applied Research in Intellectual Disabilities, 31, 454-458. https://doi.org/10.1111/jar.12423

[18] Patton, K.A., Ware, R., McPherson, L., Emerson, E. and Lennox, N. (2018) Parent-Related Stress of Male and Female Carers of Adolescents with Intellectual Disabilities and Carers of Children within the General Population: A Cross-Sectional Comparison. Journal of Applied Research in Intellectual Disabilities, 31, 51-61. https://doi.org/10.1111/jar.12292

[19] Luijkx, J., van der Putten, A.A.J. and Vlaskamp, C. (2017) Time Use of Parents Raising Children with Severe or Profound Intellectual and Multiple Disabilities. Child: Care, Health and Development, 43, 518-526. https://doi.org/10.1111/cch.12446

[20] Qian, X.L., Yarnal, C.M. and Almeida, D.M. (2014) Does Leisure Time Moderate or Mediate the Effect of Daily Stress on Positive Affect? An Examination using Eight-Day Diary Data. Journal of Leisure Research, 46, 106-124. 
https://doi.org/10.1080/00222216.2014.11950315

[21] Sirgy, M.J. (2012) Leisure Well-Being. In: The Psychology of Quality of Life, Springer Science+Business Media, Dordrecht, 401-416.

https://doi.org/10.1007/978-94-007-4405-9 22

[22] Thomas, M., Hunt, A., Hurley, M., Robertson, S. and Carter, B. (2011) Time-Use Diaries Are Acceptable to Parents with a Disabled Preschool Child and Are Helpful in Understanding Families' Daily Lives. Child: Care, Health and Development, 37, 168-174. https://doi.org/10.1111/j.1365-2214.2010.01156.x

[23] Ghandour, R.M., Hirai, A.H., Blumberg, S.J., Strickland, B.B. and Kogan, M.D. (2014) Financial and Nonfinancial Burden among Families of CSHCN: Changes between 2001 and 2009-2010. Academic Pediatrics, 14, 92-100.

https://doi.org/10.1016/j.acap.2013.10.001

[24] Masulani-Mwale, C., Kauye, F., Gladstone, M. and Mathanga, D. (2018) Prevalence of Psychological Distress among Parents of Children with Intellectual Disabilities in Malawi. BMC Psychiatry, 18, Article No. 146.

https://doi.org/10.1186/s12888-018-1731-x

[25] Tavakolizadeh, J., Amiri, M. and Nejad, F.R. (2017) Sexual Self-Esteem in Mothers of Normal and Mentally-Retarded Children. JPMA, 67, 929-932.

[26] Chou, Y.C. and Kröger, T. (2014) Reconciliation of Work and Care among Lone Mothers of Adults with Intellectual Disabilities: The Role and Limits of Care Capital. Health and Social Care in the Community, 22, 439-448. https://doi.org/10.1111/hsc. 12100

[27] Chou, Y.C., Kröger, T. and Pu, C.Y. (2018). Underemployment among Mothers of Children with Intellectual Disabilities. Journal of Applied Research in Intellectual Disabilities, 31, 152-158. https://doi.org/10.1111/jar.12336

[28] Konukbay, D. and Arslan, F. (2015) The Analysis of Hopelessness Levels and Problem Solving Skills of Parents with the Disabled Children. International Journal of Caring Sciences, 8, 344-355.

[29] Masulani-Mwale, C., Kauye, F., Gladstone, M. and Mathanga, D. (2019) Development of a Psycho-Social Intervention for Reducing Psychological Distress among Parents of Children with Intellectual Disabilities in Malawi. PLOS ONE, 14, e0210855. https://doi.org/10.1371/journal.pone.0210855 


\section{Appendix. Ethics Approval}

\section{The Ethics Committee of}

\section{ChongQing Medical University}

\section{Approval Notice of research paper}

Principal Investigators: Jun Ma

Title of Projects: Study on Quality of Life and its Factors of Mentally Retarded Children's Caregivers

Date Submitted: 15 December 2017

Date Reviewed: 9 Jamuary 2018

Date Approved: 22 January 2018

The Ethics Committee of Chongqing Medical University has reviewed the proposed use of human subjects in the above mentioned projects. It is recognized that the rights and the welfare of the subjects are adequately protected; the potential risks are outweighed by potential benefits. The species, strains, grade, specification and number of the animals to be used are justified. Appropriate animal care throughout the experiment, including an anesthetics, sedatives should be used. Disposition of animals at end of study euthanasia criteria and method is accordance with the code of practice for the care and use of animals for scientific purposes. We approve papers resulting from the project.

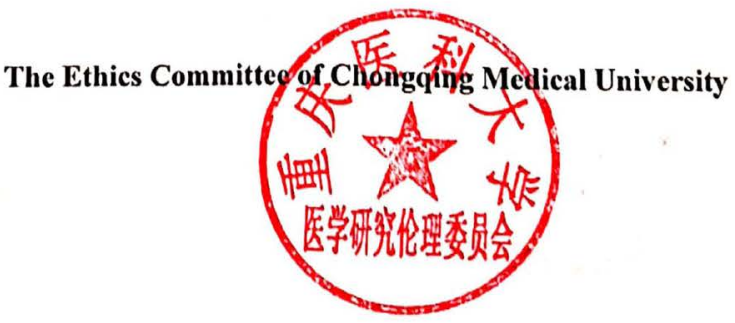

